\title{
OS IMPACTOS GERADOS NO MERCADO DE TRABALHO DE TECNOLOGIA DE INFORMAÇÃO E COMUNICAÇÃO (TIC) NO BRASIL CAUSADOS PELA TERCEIRIZAÇÃO DE SERVIÇOS ${ }^{1}$
}

\author{
Lenon Cabral de CASTRO \\ Stefano José Caetano da SILVEIRA ${ }^{3}$
}

${ }^{2}$ Graduado em Administração de Empresas pela Universidade Luterana do Brasil (ULBRA). Pós-graduando em Master em Finanças pelo Centro Universitário Ritter dos Reis (UNIRITTER). E-mail: lenoncastro@ hotmail.com

${ }^{3}$ Graduado em economia pela Universidade Federal do Rio Grande do Sul (UFRGS). Mestre em Economia do Desenvolvimento pela Universidade Federal do Rio Grande do Sul (UFRGS). E-mail: stefano.caetano@ gmail.com

Recebido em: 03/12/2015 - Aprovado em: 13/07/2016 - Disponibilizado em: 18/12/2016

\section{RESUMO:}

O presente artigo tem como proposta principal apresentar uma análise dos impactos gerados no mercado de trabalho de Tecnologia de Informação e Comunicação (TIC) no Brasil decorrentes da terceirização de serviços, tanto no tocante a atividades-meio quanto atividades-fins, abordando seu conceito, suas origens e sua aplicabilidade. Para tanto, efetuou-se uma breve revisão da bibliografia existente acerca do tema em nosso país, além de pesquisas em empresas nacionais de TIC nos setores público e privado, através de um levantamento de dados referentes a cargos, salários, benefícios e tempo de serviço que as empresas disponibilizam aos seus funcionários. O método utilizado para a realização da citada pesquisa empregou coleta de dados em empresas da área de TIC com sede e atuação no Brasil. Posteriormente, efetuouse um tratamento e uma análise destes dados. Por fim, com base em todo este estudo, buscou-se compreender se a terceirização de fato acarreta prejuízo aos trabalhadores do setor em análise, no tocante a um número maior de demissões, à queda do nível salarial, ao aumento da carga de serviço, além de poder resultar em incertezas a respeito do futuro destes trabalhadores.

Palavras-chave: Terceirização. TIC. Mercado de Trabalho. Competitividade.

\section{IMPACTS GENERATED ON INFORMATION AND COMMUNICATION TECHNOLOGY LABOR MARKET (ICT) IN BRAZIL CAUSED BY SERVICES OUTSOURCING}

\begin{abstract}
:
This article has as main purpose to present an analysis of the impacts on Information and Communication Technology labor market (ICT) in Brazil arising from the outsourcing of services, both with respect to support activities as activities worms, addressing their concept, its origins and its applicability. To this end, we performed a brief review of existing literature on the subject in our country, as well as research on national ICT companies in the public and private sectors, through a data collection related to jobs, wages, benefits and seniority that companies offer their employees. The method used to carry out the job search quote data collection in the ICT area based and active companies in Brazil. Subsequently, they performed a treatment and analysis of these data. Finally, based on all this study, we sought to understand whether the fact that outsourcing brings harm to workers in the sector in question, in relation to a larger number of layoffs, the fall of the wage level, increased service charge, and it can result in uncertainty about the future of these workers.
\end{abstract}

Keywords: Outsourcing. ICT. Job market. Competitiveness.

\footnotetext{
${ }^{1}$ Artigo a ser apresentado como avaliação parcial do curso de Pós-graduação em Negócios Master em Finanças da UniRitter Laureate International Universities, no ano de 2015, sob orientação do Prof. Stefano José Caetano da Silveira.

${ }^{3}$ Graduado em economia pela Universidade Federal do Rio Grande do Sul (UFRGS). Mestre em Economia do Desenvolvimento pela Universidade Federal do Rio Grande do Sul (UFRGS). E-mail: stefano.caetano@gmail.com 


\section{INTRODUÇÃ̃O}

Atualmente, a terceirização é uma realidade. Empresas nacionais e multinacionais vêm repassando a terceiros uma parte de seus processos que eram feitos internamente. Existem diversos motivos que levam à busca pela terceirização. As principais razões que justificam tal busca são: sucesso das inovações organizacionais e gerenciais pretendidas; concentração de esforços em vantagens competitivas, transferindo o conjunto de atividades que não correspondem ao seu core business, sejam elas de apoio, ou mesmo de produção, para outras empresas; redução de custos ou transformação de custos fixos em variáveis; e simplificação dos processos produtivos e administrativos. Além disso, a empresa terceira tende a encontrar soluções mais criativas e menos onerosas para a produção, o que elimina parte do desperdício e do comodismo que, segundo os próprios empresários, é característico das grandes corporações (DIEESE, 2007).

Apesar de aparentemente ser vantajosa para as empresas, tendo como base as pesquisas realizadas na temática, buscou-se tornar evidente a precarização na terceirização no mercado de trabalho causada em alguns segmentos, como o de Tecnologia da Informação e Comunicação (TIC). Segundo Antunes (2012), hoje as empresas buscam trabalhadores terceirizados, pois desta forma não cabe a elas as obrigações contratuais referentes aos direitos trabalhistas. Ou seja, contratam junto a outras organizações que se tornam responsáveis pelo fornecimento da mão de obra. Esta díade possui firmas que honram suas obrigações trabalhistas. Porém, infelizmente, comporta também aquelas que não as cumprem, assim tornando os seus trabalhadores vulneráveis frente à legislação vigente e mais suscetíveis à insatisfação generalizada, além de jornadas de trabalho exaustivas, fazendo-os se sentirem violentados com a presente situação.

Apesar da terceirização nas atividadesfins de vários segmentos constituir-se de uma realidade há muitos anos, como o do setor de TIC, tramitou por uma década na Câmara dos Deputados o Projeto de Lei 4.330/2004, que hoje aguarda a apreciação do Senado Federal. O citado Projeto de Lei aponta que: "O contrato de prestação de serviço pode versar sobre o desenvolvimento de atividades inerentes, acessórias ou complementares à atividade econômica da contratante" ( $§ 2^{\circ}$ do art. $4^{\circ}$ ). Sendo assim, institucionaliza as práticas da terceirização de todas as áreas da firma, permitindo, com isto, a existência de empresas sem empregados, já que o projeto de lei permite que se terceirizem todas as atividades da organização, podendo restar apenas subcontratados. A situação da terceirização no mercado de trabalho de TIC conforme já mencionado, algo que ocorre na prática em alguns setores desde a década de 
1990 - é objeto de apreciação deste estudo.

Portanto, a intenção deste artigo é analisar os impactos gerados no mercado de trabalho de TIC no Brasil causados pela terceirização de serviços, abordando seu conceito, suas origens e sua aplicabilidade. Para isso buscou-se demonstrar se a terceirização remete a diversos males aos trabalhadores do setor em análise, se provoca um número maior de demissões, baixos salários e incertezas em relação ao futuro.

\section{FUNDAMENTAÇÃO TEÓRICA}

A terceirização surgiu nos Estados Unidos, durante a Segunda Guerra Mundial (1939-1945), no momento em que a indústria de material bélico não conseguia mais abastecer o mercado. Assim, houve a necessidade de aumentar a escala de produção, com o objetivo de manter constante a oferta de armamento para os países que estavam envolvidos no conflito. Dessa forma, a saída encontrada por este setor produtivo foi “(...) remodelar a forma de produção, transferindo atividades essenciais para outras empresas" (FELÍCIO, 2004, p. 81). Neste cenário, a indústria compreendeu que deveria centralizar sua produção na fabricação de armamentos e confiar suas atividades secundárias a terceiros.

Já no Brasil, segundo D’Araujo (2004), a terceirização teve o seu início na transição entre os governos Eurico Gaspar Dutra (1945-1950) e Getúlio Vargas (1951-
1954), influenciado pela formação da Comissão Mista Brasil-Estados Unidos para o Desenvolvimento Econômico ${ }^{4}$, propiciando às empresas multinacionais se instalar no País com o objetivo de reduzir custos de mão de obra. Mas, apenas na década de 1960 houve a regulamentação que possibilitou a contratação de terceiros para a prestação de serviços, iniciando-se na área da segurança bancária. Nas palavras de Castro (2000, p. 75-76):

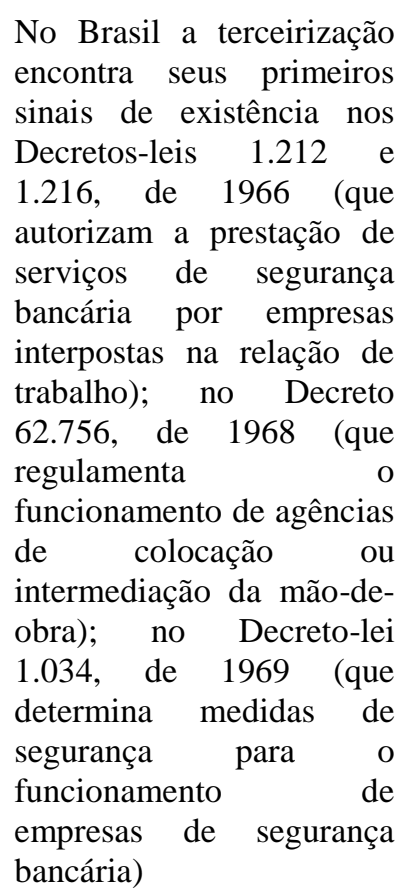

Reforçando este cenário, nos anos 1970 surgiu o modelo de trabalho conhecido como Toyotismo, idealizado por Eiji Toyoda, diretor da fábrica japonesa de veículos automotivos Toyota. Este modelo é utilizado até hoje, sendo sua principal característica a flexibilização da produção, indo no sentido inverso à premissa básica do mainstream

\footnotetext{
4 A Comissão Mista Brasil-Estados Unidos para o Desenvolvimento Econômico resultou do acordo bilateral entre estes dois países, iniciado em 1950, durante o último ano do governo Dutra. Seu principal objetivo era promover a melhoria nos setores da economia brasileira voltados à infraestrutura.
} 
anterior: o Fordismo, que defendia a produção em massa e o acúmulo de estoque. $\mathrm{O}$ Toyotismo sustenta-se a partir das técnicas do estoque mínimo, onde a estocagem é feita conforme a demanda. Quando a procura por um determinado produto é grande, a produção aumenta, quando a procura diminui a produção também diminui. Desta forma é o consumo quem determina a produção e não o inverso como o sistema fordista.

Este modelo trouxe também transformações na organização do trabalho. Ao invés de um operário por máquina, cada operário passou a conduzir várias máquinas de diferentes funções ao mesmo tempo. Neste particular, houve a junção de várias atividades em poucos postos de trabalho, podendo assim alterar os postos conforme o volume de produção.

A partir dos anos 1980, a terceirização começou a ganhar ênfase mundial através do modelo de trabalho toyotista, pois tal modelo se estrutura a partir de uma quantidade mínima de trabalhadores. Havendo aumento na produção é necessária a contratação de trabalhadores temporários ou subcontratados, além da realização de horas extras. Assim, a terceirização passou a ser utilizada no intuito de transferir a empresas subcontratadas parte dos processos de produção das firmas contratantes, para que as últimas pudessem se concentrar nas atividades-fim do seu negócio.

Com a propagação do Toyotismo e, consequentemente, da terceirização, sua aplicação e seus efeitos passaram a ser alvo de estudo tanto por parte de pesquisadores como por entidades de representação de trabalhadores. Segundo estudo elaborado em 2014 pela Central Única dos Trabalhadores (CUT), os profissionais terceirizados atingiam $26,8 \%$ do mercado de trabalho formal no Brasil naquele momento, totalizando 12,7 milhões de assalariados. Porém, este número contemplava apenas trabalhadores formais.

Desde 1993, quando foi criada a súmula 331 pelo Tribunal Superior do Trabalho (TST), buscando esclarecer o contraponto entre terceirização licita e ilícita - que é até hoje a única orientação sobre terceirização -, tem havido um aumento acelerado da quantidade de empresas terceirizadas que surgem a cada dia. Ao longo destes 22 anos, a precarização das condições de trabalho e a exploração dos trabalhadores caminham lado a lado sem que qualquer coisa seja feito a respeito.

Assim, a fim de possuir uma legislação que possa reger essas muitas relações de trabalho, é que o ex-deputado federal Sandro Mabel (PMDB-GO) criou o já referido Projeto de Lei 4.330/2004. Conforme já citado, este projeto prevê a contratação de serviços terceirizados para qualquer atividade, desde que a contratada esteja focada em uma atividade específica. As normas atingem empresas privadas, empresas públicas, sociedades de economia mista, produtores rurais e profissionais liberais. O texto somente não se aplica à administração pública direta, autarquias e fundações. 


\subsection{Argumentos a favor}

Os principais argumentos a favor do referido projeto de lei são o aumento da segurança jurídica e os ganhos de eficiência e competitividade das empresas brasileiras.

Segundo pesquisa realizada pela Federação das Indústrias do Estado de São Paulo (Fiesp), com 235 indústrias e 801 trabalhadores daquele estado, 83,8\% dos últimos acham que o PL 4.330/2004 é positivo. Na indústria, onde $73,2 \%$ das empresas utilizam serviços terceirizados, $92,1 \%$ dos entrevistados posicionaram-se a favor da regulamentação da prestação de serviço através do projeto de lei em análise. A pesquisa mostrou ainda que a insegurança jurídica, devido à falta de legislação especifica, é o principal motivo para que algumas empresas deixem de utilizar a terceirização. Atualmente, a mão de obra terceirizada na indústria paulista é de cerca de 300 mil empregados. A Fiesp estima que com a regulamentação este número possa aumentar $44 \%$, criando cerca de 130 mil novas vagas terceirizadas na cidade de São Paulo, 700 mil vagas no estado de São Paulo e 3 milhões no Brasil.

Segundo a Associação Brasileira das Empresas de Tecnologia da Informação e Comunicação (Brasscom, 2015), com a aprovação do PL 4.330/2004 o setor de TIC no Brasil será, indubitavelmente, impulsionado pelo novo diploma legal, tendo em vista a sua transversalidade em todas as atividades econômicas e seu papel indutor de inovação e eficiência pública e empresarial.

\subsection{Argumentos contrários}

Em contraponto aos argumentos da Fiesp, diversas entidades como representações sindicais e institutos de pesquisa afirmam que pode haver uma possível perda de direitos trabalhistas e de produtividade com o enfraquecimento dos vínculos entre empresas e trabalhadores.

Estudos feitos pela CUT e pelo Departamento Intersindical de Estatística e Estudos Socioeconômicos (DIEESE) apontam as diferenças que existem entre as condições de remuneração, direitos, saúde e segurança dos terceirizados em relação aos trabalhadores diretos, diferenças estas, que não serão corrigidas pelo PL 4.330/2004.

Tais estudos mostram que a renda dos trabalhadores terceirizados é $24 \%$ menor em relação aos trabalhadores formais. Além disto, os primeiros executam uma carga horária de três horas a mais semanalmente, possuem maior rotatividade, permanecem cerca de três anos a menos nos serviços, e estão mais expostos a acidentes e mortes no trabalho.

A CUT defende que haja uma regulamentação para que os abusos sejam evitados e que tal regulamentação se dê através de uma legislação que proteja os trabalhadores e combata o processo de precarização que se estende pelo mercado de trabalho no Brasil, que o PL 4.330/2004 tenta legalizar e ampliar.

Segundo Chade (2015), em artigo 
publicado no jornal "O Estado de São Paulo”, para a Organização Internacional do Trabalho (OIT) a proposta em questão representa uma grande ameaça aos direitos sociais e poderia levar à intensificação das desigualdades socioeconômicas.

Por fim, o Sindicato dos Trabalhadores em Processamento de Dados do estado do Rio Grande do Sul (Sindppd/RS) é contra o PL 4.330/2004. Segundo seus representantes, os trabalhadores podem sofrer graves prejuízos caso o projeto de lei venha a ser aprovado, pois poderá estar ameaçada a garantia de direitos trabalhistas importantes como férias, $13^{\circ}$ salário, descanso remunerado e horas extras.

\section{PROCEDIMENTOS METODOLÓGICOS}

Para a realização da pesquisa que visa demonstrar se a terceirização de fato acarreta prejuízo aos trabalhadores do setor em análise, provocando um número maior de demissões, sendo responsável pelo baixo nível salarial, pela alta carga de serviço, além de poder resultar em incertezas a respeito do futuro desses trabalhadores, optou-se por uma pesquisa qualitativa que possibilita a leitura da realidade, pois, segundo Chizzotti (1995, p.79):

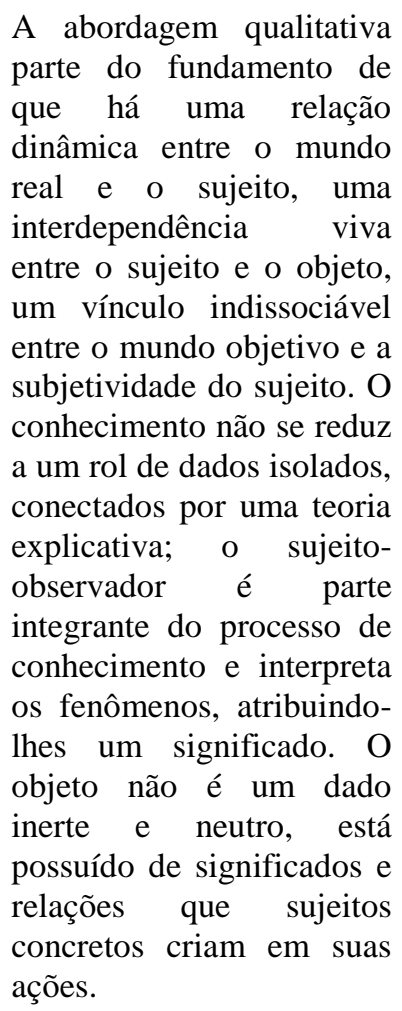

A pesquisa inicia-se pela caracterização do problema, do objetivo, dos pressupostos, das teorias e do percurso metodológico. Seu objetivo final não é finalizar o problema, mas evidenciálo, a partir de uma visão geral dentro do objetivo pesquisado. Este estudo envolveu - além do já exibido levantamento bibliográfico sobre a história da terceirização - coleta de dados junto a entidades que sustentam argumentos contra e a favor da terceirização.

Tabela 1 - Empresas participantes da pesquisa.

\begin{tabular}{|c|c|c|c|c|}
\hline Empresa & Atividade & Setor & Cidade & Estado \\
\hline Stefanini It Solutions & Meio & Privado & Porto Alegre & RS \\
\hline Verbo Tecnologia & Fim & Privado & Porto Alegre & RS \\
\hline PROCERGS & Fim & Público & Porto Alegre & RS \\
\hline PRODESP & Fim & Público & São Paulo & SP \\
\hline PRODEMGE & Fim & Público & Belo Horizonte & MG \\
\hline
\end{tabular}

Fonte: Elaborado pelo autor (2015). 
O trabalho de campo foi realizado em cinco empresas públicas e privadas, situadas em três estados brasileiros (conforme tabela 1) e contou com uma amostra não probabilística. Para isto, os elementos estabelecidos foram definidos mediante critérios determinados pelo pesquisador. Tal critério restringiu a análise a apenas dois cargos nas empresas, embora a nomenclatura dos cargos divirja entre elas. Ainda assim, as atividades desenvolvidas nas funções são equivalentes.

Foram pesquisados profissionais que atuam na área de software, que desenvolvem atividades iguais ou semelhantes aos cargos de Analista-Programador, nos níveis Júnior,
Pleno e Sênior, e Analista de Sistemas nos níveis Júnior e Pleno. Conforme já mencionado, como nem todas as empresas que participaram desta pesquisa possuem cargos com estas nomenclaturas, foi criado, para fins de melhor classificação, o cargo de Profissional de Computação (PC) nos níveis de um a cinco. Desta forma, os perfis que se encaixaram como Analista-Programador e Analista de Sistemas foram classificados como PC. Para melhor compreensão, foi feito uma ilustração conforme tabela 2.

Tabela 2 - Nomenclatura utilizada na pesquisa para definir os cargos.

\begin{tabular}{|l|l|}
\hline $\begin{array}{c}\text { Perfil pesquisado (atividades desenvolvidas } \\
\text { iguais ou semelhantes) }\end{array}$ & \multicolumn{1}{|c|}{ Nomenclatura utilizada } \\
\hline Analista-Programador Júnior & Profissional de Computação 1 (PC1) \\
\hline Analista-Programador Pleno & Profissional de Computação 2 (PC2) \\
\hline Analista-Programador Sênior & Profissional de Computação 3 (PC3) \\
\hline Analista de Sistemas Júnior & Profissional de Computação 4 (PC4) \\
\hline Analista de Sistemas Pleno & Profissional de Computação 5 (PC5) \\
\hline
\end{tabular}

Fonte: Elaborado pelo autor (2015).

Nas empresas pesquisadas, no âmbito dos cargos selecionados, foi realizada coleta de dados referente a salários, benefícios (constituídos por vale-alimentação, valerefeição, vale-transporte, vale-combustível e auxílio-educação), tempo de serviço, carga horária dos trabalhadores e Programa de Participação por Resultados (PPR).

O procedimento utilizado para a coleta de dados foi especifico dentre as particularidades e políticas de privacidade de cada empresa. A Stefanini It Solutions, fundada em 1987 por Marco Stefanini, desde então presidente da empresa, inicialmente prestava serviços de treinamentos na área de TIC. Todavia, após alguns anos, a empresa passou a desenvolver soluções customizadas para sistemas e aplicativos e fazer manutenções de sistemas. Durante décadas, a Stefanini foi se expandindo 
internacionalmente, se tornando uma multinacional brasileira, hoje presente em mais de 33 países, voltada ao outsourcing de aplicativos e infraestrutura, Os dados fornecidos pela empresa são de profissionais contratados por ela para prestar serviços a outras organizações como terceiros.

Tabela 3 - Equiparação de cargos da empresa Stefanini It Solutios

\begin{tabular}{|c|c|}
\cline { 2 - 2 } \multicolumn{1}{c|}{} & Eargo \\
pesquisado & Stefanini It Solutions \\
\hline PC1 & Analista-Programador Júnior \\
\hline PC2 & Analista-Programador Pleno \\
\hline PC3 & Analista-Programador Sênior \\
\hline PC4 & Analista de Sistemas Júnior \\
\hline PC5 & Analista de Sistemas Pleno \\
\hline
\end{tabular}

Fonte: Elaborado pelo autor, com base em STEFANINI (2015).

Foram disponibilizados pela Stefanini os dados de quatro profissionais no cargo de Analista-Programador Júnior; sete no de Analista-Programador Pleno, 14 no de Analista-Programador Sênior, três no de Analista de Sistemas Júnior e dois no de Analista de Sistemas Pleno. Para fins de equiparação, o método utilizado foi enquadrar as atividades exercidas nos cargos, conforme mostra a tabela 3 .

Outra companhia pesquisada, a Verbo Tecnologia, pertencente ao grupo Verbo, é uma empresa de TIC especializada em oferecer serviços em desenvolvimento e implantação de sistemas, websites, lojas virtuais e sistemas web completos que abrangem desde a automação das operações da empresa, até sofisticados recursos de análise dos resultados do negócio. Os dados foram fornecidos diretamente pela firma, sendo que apenas foram disponibilizados os salários, benefícios e carga horária, sem informar o número de funcionários que ocupam os cargos, tampouco o tempo de serviço dos mesmos. Os profissionais que tiveram seus dados informados são todos contratados diretamente pela empresa no regime da CLT, ou seja, não são terceirizados. Não foi informado pela empresa se utiliza de mão de obra terceirizada na área de TIC. Para fins de equiparação, o método utilizado foi enquadrar as atividades exercidas nos cargos (conforme tabela 4). 
Tabela 4 - Equiparação de cargos da empresa Verbo Tecnologia.

\begin{tabular}{|c|c|}
\cline { 2 - 2 } \multicolumn{1}{c|}{} & Eargo \\
pesquisado & Verbo Tecnologia \\
\hline PC1 & Analista-Programador Júnior \\
\hline PC2 & Analista-Programador Pleno \\
\hline PC3 & Analista-Programador Sênior \\
\hline PC4 & Analista de Sistemas Júnior \\
\hline PC5 & Analista de Sistemas Pleno \\
\hline
\end{tabular}

Fonte: Elaborado pelo autor, com base em VERBO TECNOLOGIA (2015).

Tabela 5 - Equiparação de cargos da empresa PROCERGS.

\begin{tabular}{|c|c|}
\cline { 2 - 2 } \multicolumn{1}{c|}{} & Empresa pesquisada \\
pesquisado & PROCERGS \\
\hline PC1 & Analista de computação nível 1 e 2 \\
\hline PC2 & Analista de computação nível 3 a 6 \\
\hline PC3 & Analista de computação nível 7 e 8 \\
\hline PC4 & Analista de computação nível 9 a 12 \\
\hline PC5 & Analista de computação nível 13 a 15 \\
\hline
\end{tabular}

Fonte: Elaborado pelo autor, com base em PROCERGS (2015).

Já a Companhia de Processamento de Dados do Estado do Rio Grande do Sul (PROCERGS) é uma empresa de economia mista, que iniciou suas atividades em 1972 como órgão executor da política de informática do estado gaúcho. A PROCERGS é responsável pelo processamento de dados dos órgãos públicos estaduais, cidadãos e empresas que utilizam seus produtos e serviços no dia-a-dia. Os dados foram obtidos através do portal da transparência publica do estado do Rio Grande do Sul, sendo que o cargo utilizado na pesquisa foi o de Analista de Computação do nível 1 ao 15 , onde foram colhidas amostras de cinco profissionais em cada nível. Apesar da PROCERGS utilizar mão de obra terceirizada na área de TIC, os dados utilizados da empresa neste estudo são de profissionais contratados pelo regime da CLT. Para fins de equiparação, o método utilizado foi subdividir os níveis, conforme mostra tabela 5. 
Tabela 6 - Equiparação de cargos da empresa PRODEMGE.

\begin{tabular}{|c|c|}
\cline { 2 - 2 } \multicolumn{1}{c|}{} & Empresa pesquisada \\
\hline $\begin{array}{c}\text { Cargo } \\
\text { pesquisado }\end{array}$ & PRODEMGE \\
\hline PC1 & Analista (salário de $\mathrm{R} \$ 1.082,00$ a $\mathrm{R} \$ 5.761,00)$ \\
\hline $\mathrm{PC} 2$ & Analista (salário de $\mathrm{R} \$ 5.761,01$ a $\mathrm{R} \$ 8.101,00)$ \\
\hline $\mathrm{PC} 3$ & Analista (salário de $\mathrm{R} \$ 8.101,01$ a $\mathrm{R} \$ 10.441,00)$ \\
\hline $\mathrm{PC} 4$ & Analista (salário de $\mathrm{R} \$ 10.441,01$ a $\mathrm{R} \$ 12.781,00)$ \\
\hline PC5 & Analista (salário de $\mathrm{R} \$ 12.781,01$ a $\mathrm{R} \$ 15.121,00)$ \\
\hline
\end{tabular}

Fonte: Elaborado pelo autor, com base em PRODEMGE (2015).

Dando continuidade, a Companhia de Tecnologia da Informação do Estado de Minas Gerais (PRODEMGE), criada em 1972, tem como principais competências o processamento de dados e o tratamento de informações para os órgãos públicos, além da prestação de assistência técnica às entidades da administração pública em geral do território mineiro. Os dados foram coletados através do portal da transparência pública do estado de Minas Gerais. O cargo utilizado na pesquisa foi $\mathrm{o}$ de Analista, onde foram selecionados 123 profissionais. $\mathrm{Na}$ amostra, constaram apenas trabalhadores contratados no regime da CLT. Não foi informado pela empresa se ela emprega mão de obra terceirizada na área de TIC. Para fins de equiparação, o método utilizado foi subdividir os cargos por faixas salariais, conforme mostra a tabela 6.

Por fim, a Companhia de Processamento de Dados do Estado de São
Paulo (PRODESP), empresa pública de TIC do governo paulista, vinculada à Secretaria de Governo do Estado, é uma empresa de economia mista (sociedade anônima fechada), fundada em 1969. Seus principais acionistas são a Secretaria da Fazenda do Estado de São Paulo (SEFAZ-SP) e o Instituto de Previdência do Estado de São Paulo (IPESP). Dentre os serviços prestados, um dos principais é o armazenamento de dados (storage). Para esta pesquisa, os dados foram coletados através do portal da transparência pública do estado de São Paulo. O cargo utilizado foi o de Analista de Informática, sendo escolhidos 183 profissionais sob no regime da CLT. Não foi informado se a empresa emprega mão de obra terceirizada na área de TIC. Para fins de equiparação, o método utilizado foi subdividir os cargos por faixas salariais. 
Tabela 7 - Equiparação de cargos da empresa PRODESP.

\begin{tabular}{|c|c|}
\cline { 2 - 3 } \multicolumn{1}{c|}{} & Empresa pesquisada \\
pesquisado & PRODESP \\
\hline PC1 & Analista de Informática \\
& (salário de $\mathrm{R} \$ 4.601,00$ a $\mathrm{R} \$ 7.397,00)$ \\
\hline PC2 & Analista de Informática \\
(salário de $\mathrm{R} \$ 7.397,01$ a $\mathrm{R} \$ 10.193,00)$
\end{tabular}

Fonte: Elaborado pelo autor, com base em PRODESP (2015).

Após a coleta de dados, buscou-se analisar e interpretar as informações. Segundo Teixeira (2003, p. 191):

\begin{abstract}
A análise de dados é o processo de formação de sentido além dos dados, e esta formação se dá consolidando, limitando e interpretando o que as pessoas disseram e o que o pesquisador viu e leu, isto é, o processo de formação de significado. A análise dos dados é um processo complexo que envolve retrocessos entre dados pouco concretos $\mathrm{e}$ conceitos abstratos, entre raciocínio indutivo e dedutivo, entre descrição e interpretação.
\end{abstract}

O procedimento metodológico utilizado na interpretação de os dados baseou-se na análise de conteúdo, que é uma metodologia de pesquisa utilizada para interpretar e descrever o conteúdo de documentos e textos. Essa análise é conduzida por descrições sistemáticas, que podem ser qualitativas e quantitativas, assim reinterpretando as mensagens para que se possa atingir uma compreensão de seus significados em um nível que ultrapassa uma leitura comum (MORAES, 1999).

Essa técnica teve origem nos Estados Unidos no início do século $\mathrm{XX}$, segundo Mozzato e Grzybovski (2011), quando foi estudada a propaganda na Primeira Guerra Mundial (1914-1918). Neste período a linguística e a análise de conteúdo ainda não se relacionavam, por mais que tivessem a linguagem como algo em comum.

Baseado neste procedimento de análise, os dados coletados referente a cargos, salários, benefícios, tempo de serviço, carga horária e PPR foram medidos e classificados em indicadores visando a uma análise fidedigna, conforme demonstrado nas tabelas a seguir. 
Tabela 8 - Dados coletados na pesquisa: empresa Stefanini It Solutios.

\begin{tabular}{|c|c|c|c|c|c|}
\hline & \multicolumn{5}{|c|}{ Stefanini It Solutios } \\
\hline & Salário & Benefícios & \begin{tabular}{|l} 
Tempo \\
de \\
Serviço \\
(anos)
\end{tabular} & $\begin{array}{l}\text { Carga } \\
\text { Horária } \\
\text { Semanal }\end{array}$ & $\begin{array}{c}\text { PPR } \\
\text { (semestral) }\end{array}$ \\
\hline PC1 & $\mathrm{R} \$ 2.800,00$ & $\mathrm{R} \$ 739,97$ & 0.6 & $44 \mathrm{~h}$ & $N / P$ \\
\hline PC2 & $\mathrm{R} \$ 3.405,96$ & $\mathrm{R} \$ 829,64$ & 0.6 & $44 \mathrm{~h}$ & $N / P$ \\
\hline PC3 & $\mathrm{R} \$ 4.475,52$ & $\mathrm{R} \$ 1.077,43$ & 3.5 & $44 \mathrm{~h}$ & $N / P$ \\
\hline PC4 & $\mathrm{R} \$ 2.600,00$ & $\mathrm{R} \$ 632,97$ & 2.9 & $44 \mathrm{~h}$ & $N / P$ \\
\hline PC5 & $\mathrm{R} \$ 3.504,25$ & $\mathrm{R} \$ 1.148,28$ & 4 & $44 \mathrm{~h}$ & $N / P$ \\
\hline
\end{tabular}

Fonte: Elaborado pelo autor, com base em Stefanini It Solutions (2015).

N/P - Não Possui

Tabela 9 - Dados coletados na pesquisa: empresa Verbo Tecnologia.

\begin{tabular}{|c|c|c|c|c|c|}
\cline { 2 - 6 } \multicolumn{1}{c|}{} & \multicolumn{5}{c|}{ Verbo Tecnologia } \\
\cline { 2 - 6 } \multicolumn{1}{c|}{} & Salário & Benefícios & $\begin{array}{c}\text { Tempo } \\
\text { de } \\
\text { Serviço }\end{array}$ & $\begin{array}{c}\text { Carga } \\
\text { Horária } \\
\text { Semanal }\end{array}$ & $\begin{array}{c}\text { PPR } \\
\text { (semestral) }\end{array}$ \\
\hline $\mathrm{PC} 1$ & $\mathrm{R} \$ 3.400,00$ & $\mathrm{R} \$ 556,50$ & $N / D$ & $40 \mathrm{~h}$ & $N / P$ \\
\hline $\mathrm{PC} 2$ & $\mathrm{R} \$ 4.700,00$ & $\mathrm{R} \$ 556,50$ & $N / D$ & $40 \mathrm{~h}$ & $N / P$ \\
\hline $\mathrm{PC} 3$ & $\mathrm{R} \$ 5.300,00$ & $\mathrm{R} \$ 556,50$ & $N / D$ & $40 \mathrm{~h}$ & $N / P$ \\
\hline $\mathrm{PC} 4$ & $\mathrm{R} \$ 6.800,00$ & $\mathrm{R} \$ 556,50$ & $N / D$ & $40 \mathrm{~h}$ & $N / P$ \\
\hline PC5 & $\mathrm{R} \$ 7.150,00$ & $\mathrm{R} \$ 556,50$ & $N / D$ & $40 \mathrm{~h}$ & $N / P$ \\
\hline
\end{tabular}

Fonte: Elaborado pelo autor, com base em Verbo Tecnologia (2015).

N/D - Não Declarado; N/P - Não Possui.

Tabela 10 - Dados coletados na pesquisa: empresa PROCERGS.

\begin{tabular}{|c|c|c|c|c|c|}
\cline { 2 - 6 } \multicolumn{1}{c|}{} & \multicolumn{5}{c|}{ PROCERGS } \\
\cline { 2 - 6 } & Salário & Benefícios & $\begin{array}{c}\text { Tempo } \\
\text { de } \\
\text { Serviço } \\
\text { (anos) }\end{array}$ & $\begin{array}{c}\text { Carga } \\
\text { Horária } \\
\text { Semanal }\end{array}$ & $\begin{array}{c}\text { PPR } \\
\text { (semestral) }\end{array}$ \\
\hline PC1 & $\mathrm{R} \$ 4.816,68$ & $\mathrm{R} \$ 1.066,77$ & 4.8 & $40 \mathrm{~h}$ & $\mathrm{R} \$ 2.408,34$ \\
\hline $\mathrm{PC} 2$ & $\mathrm{R} \$ 6.446,82$ & $\mathrm{R} \$ 1.066,77$ & 11.5 & $40 \mathrm{~h}$ & $\mathrm{R} \$ 3.223,41$ \\
\hline $\mathrm{PC} 3$ & $\mathrm{R} \$ 8.741,46$ & $\mathrm{R} \$ 1.066,77$ & 20 & $40 \mathrm{~h}$ & $\mathrm{R} \$ 4.370,73$ \\
\hline $\mathrm{PC} 4$ & $\mathrm{R} \$ 10.733,41$ & $\mathrm{R} \$ 1.066,77$ & 26.8 & $40 \mathrm{~h}$ & $\mathrm{R} \$ 5.366,70$ \\
\hline PC5 & $\mathrm{R} \$ 13.064,65$ & $\mathrm{R} \$ 1.066,77$ & 31.8 & $40 \mathrm{~h}$ & $\mathrm{R} \$ 6.532,32$ \\
\hline
\end{tabular}

Fonte: Elaborado pelo autor, com base em PROCERGS (2015). 
Tabela 11 - Dados coletados na pesquisa: empresa PRODESP.

\begin{tabular}{|c|c|c|c|c|c|}
\hline & \multicolumn{5}{|c|}{ PRODESP } \\
\hline & Salário & Benefícios & $\begin{array}{l}\text { Tempo } \\
\text { de } \\
\text { Serviço }\end{array}$ & $\begin{array}{c}\text { Carga } \\
\text { Horária } \\
\text { Semanal }\end{array}$ & $\begin{array}{c}\text { PPR } \\
\text { (semestral) }\end{array}$ \\
\hline PC1 & $\mathrm{R} \$ 5.571,67$ & $N / D$ & $N / D$ & $40 \mathrm{~h}$ & $N / D$ \\
\hline $\mathrm{PC} 2$ & $\mathrm{R} \$ 8.784,04$ & $N / D$ & $N / D$ & $40 \mathrm{~h}$ & $N / D$ \\
\hline PC3 & $\mathrm{R} \$ 12.568,26$ & $N / D$ & $N / D$ & $40 \mathrm{~h}$ & $N / D$ \\
\hline PC4 & $\mathrm{R} \$ 16.690,15$ & $N / D$ & $N / D$ & $40 \mathrm{~h}$ & $N / D$ \\
\hline PC5 & $\mathrm{R} \$ 19.585,50$ & $N / D$ & $N / D$ & $40 \mathrm{~h}$ & $N / D$ \\
\hline
\end{tabular}

Fonte: Elaborado pelo autor, com base em PRODESP (2015).

N/D - Não Declarado.

Tabela 12 - Dados coletados na pesquisa: empresa PRODEMGE

\begin{tabular}{|c|c|c|c|c|c|}
\hline & \multicolumn{5}{|c|}{ PRODEMGE } \\
\hline & Salário & Benefícios & $\begin{array}{l}\text { Tempo } \\
\text { de } \\
\text { Serviço }\end{array}$ & $\begin{array}{c}\text { Carga } \\
\text { Horária } \\
\text { Semanal }\end{array}$ & $\begin{array}{c}\text { PPR } \\
\text { (semestral) }\end{array}$ \\
\hline PC1 & $\mathrm{R} \$ 4.097,96$ & $N / D$ & $N / D$ & $44 \mathrm{~h}$ & $N / D$ \\
\hline PC2 & $\mathrm{R} \$ 6.736,45$ & $N / D$ & $N / D$ & $44 \mathrm{~h}$ & $N / D$ \\
\hline PC3 & $\mathrm{R} \$ 9.160,58$ & $N / D$ & $N / D$ & $44 \mathrm{~h}$ & $N / D$ \\
\hline PC4 & $\mathrm{R} \$ 11.800,53$ & $N / D$ & $N / D$ & $44 \mathrm{~h}$ & $N / D$ \\
\hline PC5 & $\mathrm{R} \$ 13.660,31$ & $N / D$ & $N / D$ & $44 \mathrm{~h}$ & $N / D$ \\
\hline
\end{tabular}

Fonte: Elaborado pelo autor, com base em PRODEMGE (2015).

N/D - Não Declarado.

Com base nos dados coletados na pesquisa de campo, e devidamente ordenados em indicadores, será apresentada no próximo item a análise dos mesmos.

\section{ANÁLISE DOS DADOS}

A análise dos dados foi realizada utilizando uma linguagem respectiva, fundada a partir de técnicas, métodos, conceitos e proposições, desconsiderando os diferentes custos de vida das cidades de Porto Alegre, São Paulo e Belo Horizonte. Para que pudesse ocorrer, a fase de pesquisa foi efetuada através de contatos presenciais, por telefone e por mail com empresas da área de TIC que atuam em diversas regiões do Brasil. Porém, por questões estratégicas e/ou internas, muitas destas empresas alegaram não poder fornecer as informações solicitadas.

Conforme a tabela 13, o modelo utilizado para analisar os dados obtidos e apresentados na seção 3 foi elaborado através de uma escala criada pelo autor onde são medidos os indicadores salários, benefícios, 
tempo de serviço, carga horária e PPR dos profissionais de TIC das empresas pesquisadas. Esta análise tem como objetivo identificar em que condições se encontram tanto os profissionais terceirizados como os profissionais contratados de forma direta. A escala foi elaborada de forma numérica que vai de um a cinco, onde o número um representa o melhor nível (primeiro lugar), recebendo cinco pontos, e o número cinco o pior nível (último lugar), fazendo jus a somente um ponto. A exceção foi o indicador Salário que, por ser o de maior importância, recebeu o triplo da pontuação estipulada. As empresas que não divulgaram ou não contam com um ou outro indicador foram classificados como sendo do pior nível. Em caso de empate, as companhias receberam a mesma colocação.

$\mathrm{O}$ único indicador em que todas as empresas apresentaram valores foi Salário, que, conforme já mencionado, por ser considerado o indicador mais importante, teve sua pontuação triplicada. Em relação aos Benefícios, as companhias PRODESP e PRODEMGE nada informaram a respeito, motivo pelo qual empataram na última colocação neste indicador. De forma análoga está Tempo de Serviço, pois apenas as companhias PROCERGS e Stefanini forneceram dados, ficando desta forma com a primeira e segunda colocação, respectivamente.

Tabela 13 - Análise dos dados

\begin{tabular}{|c|c|c|c|c|c|c|c|}
\hline & Cargo & $\begin{array}{l}\text { Salário } \\
(1)\end{array}$ & $\begin{array}{l}\text { Benefícios } \\
\text { (2) }\end{array}$ & $\begin{array}{c}\text { Tempo de } \\
\text { Serviço (2) }\end{array}$ & $\begin{array}{l}\text { Carga Horária } \\
\text { Semanal (2) }\end{array}$ & $\begin{array}{c}\text { PPR } \\
(2)\end{array}$ & Pontos \\
\hline \multirow{5}{*}{$\begin{array}{l}\text { Stefanini It } \\
\text { Solutios }\end{array}$} & $\mathrm{PC} 1$ & $5^{\circ}$ & $2^{\circ}$ & $2^{\circ}$ & $4^{\circ}$ & $2^{\circ}$ & 17 \\
\hline & PC2 & $5^{\circ}$ & $2^{\circ}$ & $2^{\circ}$ & $4^{\circ}$ & $2^{\circ}$ & 17 \\
\hline & PC3 & $5^{\circ}$ & $1^{\circ}$ & $2^{\circ}$ & $4^{\circ}$ & $2^{\circ}$ & 18 \\
\hline & PC4 & $5^{\circ}$ & $2^{\circ}$ & $2^{\circ}$ & $4^{\circ}$ & $2^{\circ}$ & 17 \\
\hline & PC5 & $5^{\circ}$ & $1^{\mathrm{o}}$ & $2^{\circ}$ & $4^{\circ}$ & $2^{\circ}$ & 18 \\
\hline Total & & & & & & & 87 \\
\hline \multirow{5}{*}{$\begin{array}{c}\text { Verbo } \\
\text { Tecnologia }\end{array}$} & PC1 & $4^{\circ}$ & $3^{\circ}$ & $3^{\circ}$ & $1^{\circ}$ & $2^{\circ}$ & 21 \\
\hline & $\mathrm{PC} 2$ & $4^{\circ}$ & $3^{\circ}$ & $3^{\circ}$ & $1^{\circ}$ & $2^{\circ}$ & 21 \\
\hline & PC3 & $4^{\circ}$ & $3^{\circ}$ & $3^{\circ}$ & $1^{\circ}$ & $2^{\circ}$ & 21 \\
\hline & PC4 & $4^{\circ}$ & $3^{\circ}$ & $3^{\circ}$ & $1^{\circ}$ & $2^{\circ}$ & 21 \\
\hline & PC5 & $4^{\circ}$ & $3^{\circ}$ & $3^{\circ}$ & $1^{\circ}$ & $2^{\circ}$ & 21 \\
\hline Total & & & & & & & 105 \\
\hline \multirow{5}{*}{ PROCERGS } & PC1 & $2^{\circ}$ & $1^{\circ}$ & $1^{\circ}$ & $1^{\circ}$ & $1^{\circ}$ & 32 \\
\hline & $\mathrm{PC} 2$ & $3^{\circ}$ & $1^{\circ}$ & $1^{\circ}$ & $1^{\circ}$ & $1^{\circ}$ & 29 \\
\hline & PC3 & $3^{\circ}$ & $2^{\circ}$ & $1^{\circ}$ & $1^{\circ}$ & $1^{\circ}$ & 28 \\
\hline & PC4 & $3^{\circ}$ & $1^{\circ}$ & $1^{\circ}$ & $1^{\circ}$ & $1^{\circ}$ & 29 \\
\hline & PC5 & $3^{\circ}$ & $2^{\circ}$ & $1^{\circ}$ & $1^{\circ}$ & $1^{\circ}$ & 28 \\
\hline Total & & & & & & & 146 \\
\hline PRODESP & $\mathrm{PC} 1$ & $1^{\circ}$ & $4^{\circ}$ & $3^{\circ}$ & $1^{\circ}$ & $2^{\circ}$ & 29 \\
\hline
\end{tabular}




\begin{tabular}{|c|c|c|c|c|c|c|c|}
\hline & $\mathrm{PC} 2$ & $1^{\mathrm{o}}$ & $4^{\circ}$ & $3^{\circ}$ & $1^{\mathrm{o}}$ & $2^{o}$ & 29 \\
\hline & PC3 & $1^{\circ}$ & $4^{\circ}$ & $3^{\circ}$ & $1^{\circ}$ & $2^{\circ}$ & 29 \\
\hline & PC4 & $1^{\circ}$ & $4^{\circ}$ & $3^{\circ}$ & $1^{\circ}$ & $2^{\circ}$ & 29 \\
\hline & PC5 & $1^{\circ}$ & $4^{\circ}$ & $3^{\circ}$ & $1^{\circ}$ & $2^{\circ}$ & 29 \\
\hline Total & & & & $3^{\circ}$ & & & 145 \\
\hline \multirow{5}{*}{ PRODEMGE } & $\mathrm{PC} 1$ & $3^{\circ}$ & $4^{\circ}$ & $3^{\circ}$ & $4^{\circ}$ & $2^{\circ}$ & 20 \\
\hline & PC2 & $2^{\circ}$ & $4^{\circ}$ & $3^{\circ}$ & $4^{\circ}$ & $2^{\circ}$ & 23 \\
\hline & $\mathrm{PC} 3$ & $2^{\circ}$ & $4^{\circ}$ & $3^{\circ}$ & $4^{\circ}$ & $2^{\circ}$ & 23 \\
\hline & PC4 & $2^{\circ}$ & $4^{\circ}$ & $3^{\circ}$ & $4^{\circ}$ & $2^{\circ}$ & 23 \\
\hline & PC5 & $2^{\circ}$ & $4^{\circ}$ & $3^{\circ}$ & $4^{\circ}$ & $2^{\circ}$ & 23 \\
\hline Total & & & & & & & 112 \\
\hline
\end{tabular}

Fonte: Elaborado pelo autor (2015).

(1) Para o indicador Salário: $1^{\circ}$ colocado $=15$ pontos; $2^{\circ}=12$ pontos; $3^{\circ}=9$ pontos; $4^{\circ}=6$ pontos; $5^{\mathrm{a}}=3$ pontos.

(2) Para os demais indicadores: $1^{\circ}$ colocado $=5$ pontos; $2^{\circ}=4$ pontos; $3^{\circ}=3$ pontos; $4^{\circ}=2$ pontos; $5^{a}=1$ ponto.

\section{Já em relação à Carga Horária}

Semanal, todas as empresas que participam deste estudo apresentaram valores. Como três delas (PROCERGS, PRODESP e Verbo Tecnologia) possuem carga horária de 40 horas semanais, empataram no primeiro lugar. As demais (Stefanini e PRODEMGE), que tem uma jornada de trabalho de 44 horas por semana, ficaram juntas na quarta e última colocação. Por fim, o indicador PPR que somente a PROCERGS declarou possuir. PRODEMGE e PRODESP não informaram se adotaram tal programa de participação nos resultados. Por sua vez, Stefanini e Verbo
Tecnologia afirmaram não terem implantado o referido programa. Sendo assim, a PROCERGS obteve o primeiro lugar em relação a este indicador, ficando todas as demais empatadas na segunda colocação.

A tabela 14 apresenta o resultado final de os dados analisados através da natureza de cada empresa em seu segmento (setor), visto que este trabalho tem como objetivo analisar apenas as condições em que se encontram no mercado de trabalho tanto os profissionais terceirizados quanto os profissionais contratados de forma direta, e não analisar qual a melhor ou pior empresa.

Tabela 14 - Resultado

\begin{tabular}{|c|c|c|c|}
\hline Colocação & Pontuação & Atividade & Setor \\
\hline $1^{\circ}$ & 146 & Fim & Público \\
\hline $2^{\circ}$ & 145 & Fim & Público \\
\hline $3^{\circ}$ & 112 & Fim & Público \\
\hline $4^{\circ}$ & 105 & Fim & Privado \\
\hline $5^{\circ}$ & 87 & Meio & Privado \\
\hline
\end{tabular}

Fonte: Elaborado pelo autor (2015). 
Conforme pode ser constatado na tabela 14, os profissionais contratados de forma direta tiveram um melhor desempenho na pesquisa. Também pode ser observado que o setor público oferece as melhores condições aos trabalhadores de TIC, devido aos melhores salários e à baixa rotatividade, fruto da estabilidade oferecida aos funcionários públicos. Já os trabalhadores contratados diretamente pelas empresas do setor privado, sob o regime da CLT, tiveram um resultado inferior comparado aos profissionais do setor público. Porém, quando confrontados aos terceirizados, obtiveram um resultado melhor. Por fim, os profissionais terceirizados tiveram o pior resultado dentre os indicadores pesquisados.

A análise de os dados revela a precarização da terceirização, acarretando prejuízos aos trabalhadores, dado receberem salários menores quando comparados com profissionais do mesmo cargo contratados de forma direta, entre empresas públicas e privadas. Como se não bastasse, estes profissionais tem uma alta rotatividade, permanecendo pouco tempo na empresa, além de uma carga horária maior. $\mathrm{O}$ resultado desta pesquisa vai ao encontro dos estudos realizados pela CUT e pelo DIEESE, que demonstram que a renda dos trabalhadores terceirizados é cerca de $24 \%$ menor em relação aos trabalhadores da mesma classe que não são terceiros, além de executarem uma carga horária maior semanalmente, possuírem maior rotatividade e permanecerem cerca de três anos a menos nos postos de trabalho.

\section{CONSIDERAÇÕES FINAIS}

Esta pesquisa buscou apurar se de fato a terceirização acarreta prejuízo aos trabalhadores do setor de TIC no Brasil. Primeiramente, ela iniciou apresentando a história da terceirização, desde sua origem nos Estados Unidos durante a Segunda Guerra Mundial (1939-1945), passando pelo seu primórdio no Brasil no início da década de 1950, além de abordar seu reconhecimento internacional a partir do modelo de trabalho conhecido como Toyotismo, e finalizando pela apresentação do cenário atual da terceirização no Brasil no setor de TIC.

Contudo, ainda que a terceirização sobretudo nas atividades-meio - esteja disseminada em todos os setores no Brasil, ela não acontece de forma satisfatória no setor de TIC. Pode-se atribuir esta ocorrência à ambição de algumas empresas que utilizam a prestação de serviço terceirizada como massa de trabalho exaustiva, ferindo os direitos dos trabalhadores, dado visarem apenas o lucro e seu próprio crescimento. Apesar de não ser o foco deste estudo, pode-se afirmar que de forma geral isto não está presente apenas no setor de TIC. Comumente as empresas prestadoras reduzem os valores de suas propostas para atraírem clientes. Porém, essa tática faz com que os salários oferecidos aos trabalhadores sejam mais baixos, remetendo a 
uma alta rotatividade nas empresas.

Segundo Cruz (2012), a referida alta rotatividade dos trabalhadores terceirizados, somente no estado de São Paulo acarreta que, em média, estes profissionais contribuam para a Previdência Social em apenas sete dos 12 meses do ano. Tal situação faz com que contribuam menos a Previdência durante suas carreiras, alimentando ainda mais o déficit do sistema previdenciário, além de causar um impacto negativo nas finanças públicas, através do pagamento do seguro-desemprego. No longo prazo, estes trabalhadores acabam tendo uma renda mais reduzida na aposentadoria.

No setor empresarial, a terceirização é tida como uma das principais alternativas para redução de custos, possibilitando à empresa contratante entregar a terceiros suas atividades-meio, podendo assim investir sua atenção em suas atividades-fim. Todavia, em alguns setores, como o de TIC, mesmo que parcialmente, até mesmo as atividades-fim das organizações vêm sendo executadas por mão de obra terceirizada. Portanto, é visível a necessidade de uma lei que venha regulamentar a terceirização de serviços. Mesmo que elaborado há mais de uma década, o Projeto de Lei 4.330/2004, que trata do tema, ainda aguarda a apreciação do Senado Federal. Apesar de polêmico e controverso, espera-se que ele traga algum alento aos trabalhadores que hoje se encontram na condição de terceirizados.

Portanto, mesmo reconhecendo o caráter limitado deste estudo, mas imaginando que ele possa ser o ponto de partida para uma análise mais aprofundada à respeito da temática apresentada, cabe ressaltar que neste momento a única certeza de fato é a necessidade de uma legislação que abranja tanto o empregador como o empregado, que consiga harmonizar e balancear essas relações, sem prejudicar a execução dos serviços e a qualidade de vida e direitos desses trabalhadores, como pode ser visualizado nesta pesquisa.

\section{REFERÊNCIAS}

ANTUNES, Ricardo. Terceirização: porta de entrada para a precarização. Disponível em: <http://www.ihu.unisinos.br/entrevistas/509660 -terceirizacao-porta-de-entrada-para-aprecarizacao>. Acesso em: 23 jul 2015.

BARDIN, L. Análise de conteúdo. Lisboa: Edições 70, 1979.

BRASSCOM, Associação Brasileira das Empresas de Tecnologia da Informação e Comunicação. Pela aprovação do Projeto de Lei ${ }^{\circ}$ 4.330/2004. Disponível em: $<$ http://www.brasscom.org.br/brasscom/Portugu es/detPosicionamento.php?codPosicionamento= 805>. Acesso em: 22 set 2015.

CASTRO, Rubens Ferreira de. A Terceirização no Direito do Trabalho. São Paulo: Malheiros, 2000.

CHADE, Jamil. Para OIT, Terceirização ameaça direito de trabalhadores. Estadão. Disponível em:

$<$ http://economia.estadao.com.br/noticias/geral, para-oit-terceirizacao-ameaca-direito-detrabalhadores,1689646>. Acesso em: 11 set 2015.

CHIZZOTTI, Antonio. Pesquisa em Ciências Humanas e Sociais. $2^{\circ}$ Edição. São Pualo: Cortez, 1995. 
CRUZ, Elaine Patricia. Rotatividade de trabalhadores terceirizados contribui para o déficit da Previdência, diz presidente do Ipea. Agência Brasil. Disponível em: < http://memoria.ebc.com.br/agenciabrasil/noticia /2012-03-05/rotatividade-de-trabalhadoresterceirizados-contribui-para-deficit-daprevidencia-diz-presidente-do-i>. Acesso em: 26 nov 2015.

CUT, Central Única dos Trabalhadores. Terceirização e Desenvolvimento: Uma conta que não fecha. 2014. Disponível em:

<http://www.cut.org.br/system/uploads/ck/files/ Dossie-Terceirizacao-e-Desenvolvimento.pdf $>$. Acesso em: 09 jul 2015.

D'ARAUJO, Maria Celina. Comissão Mista Brasil-Estados Unidos para o Desenvolvimento Econômico. In: E ELE voltou... o segundo governo Vargas. Era Vargas: anos 20 a 1945 [on-line]. Rio de Janeiro: CPDOC, 2004. Disponível em:

$<$ http://www.cpdoc.fgv.br/nav_gv/htm/3E_ele_ voltou/Comissao_mista_Brasil_EUA.asp>. Acesso em: 23 jan. 2006.

DIEESE, Departamento Intersindical de Estatísticas e Estudos Socioeconômicos. O Processo de Terceirização e Seus Efeitos Sobre os Trabalhadores no Brasil. 2007. Relatório técnico. Disponível em: $<\mathrm{http} / / /$ www3.mte.gov.br/observatorio/Prod03 2007.pdf >. Acesso em: 07 jul 2015.

FELÍCIO, Alessandra Metzger. Terceirização: Caracterização, Origem e Evolução Jurídica. Belo Horizonte: Mandamentos, 2004. p. 81.

FIESP, Federação das Indústrias do Estado de São Paulo. Terceirização é aprovada por $\mathbf{8 3 , 8 \%}$ dos trabalhadores e por $\mathbf{9 2 , 1 \%}$ das indústrias de SP. Disponível em:

$<$ http://www.fiesp.com.br/noticias/terceirizacao -e-aprovada-por-838-dos-trabalhadores-e-por921-das-industrias-do-estado-de-sao-paulo/ > . Acesso em: 11 set 2015.

MORAES, Roque. Análise de conteúdo. Revista Educação, Porto Alegre, v. 22, n. 37, p. 7-32, 1999.
MOZZATO, Anelise Rebelato; GRZYBOVSKI, Denize. Análise de Conteúdo como Técnica de Análise de Dados Qualitativos no Campo da Administração: Potencial e Desafios. RAC, Curitiba, v. 15, n. 4, p. 731-747, Jul./Ago. 2011.

PROCERGS, Companhia de Processamento de Dados do Estado do Rio Grande do Sul.

Disponível em: <

http://www.procergs.rs.gov.br/ > . Acesso em: 01 out 2015.

PRODEMGE, Companhia de Tecnologia da Informação do Estado de Minas Gerais.

Disponível em: <http://www.prodemge.gov.br/ >. Acesso em: 01 out 2015.

PRODESP. Disponível em: <http://www.prodesp.sp.gov.br/index.asp>. Acesso em: 01 out 2015.

SINDPPD/RS, Sindicato dos Trabalhadores em Processamento de Dados do estado do Rio Grande do Sul. Vamos barrar o PL 4330 que regulamenta a terceirização. Disponível em: $<$ http://www.sindppd-rs.org.br/vamos-barrar-opl-4330-que-regulamenta-a-terceirizacao/>. Acesso em: 24 set 2015.

STEFANINI IT SOLUTIONS. Disponível em: <http://www.stefanini.com/br/>. Acesso em: 01 out 2015.

TEIXEIRA, Enise Barth. A Análise de Dados na Pesquisa Científica: importância e desafios em estudos organizacionais. Editora Unijuí, Ijuí, ano 1, n. 2, p. 177-201, jul/dez. 2003.

TERRIBILI, Armando Filho. Outsourcing: histórico e conceitos. Disponível em: < http://www.metaanalise.com.br/inteligenciadem ercado/index.php?option=com_content $\& v i e w=a$ rticle\&id=9679:outsourcing-historico-econceitos\&catid=1:ponto-devista \&Itemid=353>. Acesso em: 12 nov 2015 .

VERBO TECNOLOGIA. Disponível em: <http://www.verbotecnologia.com.br/>. Acesso em: 01 out 2015. 